\title{
Skeletal muscle calcium channel ryanodine and the development of pale, soft, and exudative meat in poultry
}

\author{
F.G. Paião ${ }^{1}$ L.M. Ferracin ${ }^{2}$, M. Pedrão ${ }^{1}$, T. Kato $^{1}$ and M. Shimokomaki ${ }^{1,2}$ \\ ${ }^{1}$ Universidade Tecnológica Federal do Paraná, Londrina, PR, Brasil \\ ${ }^{2}$ Departamento de Medicina Veterinária e Preventiva, \\ Universidade Estadual de Londrina, Londrina, PR, Brasil \\ Corresponding author: M. Shimokomaki \\ E-mail:mshimo@uel.br
}

Genet. Mol. Res. 12 (3): 3017-3027 (2013)

Received December 12, 2012

Accepted June 19, 2013

Published August 20, 2013

DOI http://dx.doi.org/10.4238/2013.August.20.3

ABSTRACT. The development of pale, soft, and exudative (PSE) breast fillet meat has become an economic burden for the poultry industry worldwide. PSE meat results in 1.0-1.5\% loss in moisture and carcass weight, and a 2010 estimate of the Brazilian annual production put the economic loss due to PSE at over US\$30 million. In the USA, PSE has caused an annual loss of up to US\$200 million to the poultry industries. The underlying causes of the color abnormality in PSE meat are not fully understood. However, the likely physiological origin of PSE broiler meat is an excessive release of $\mathrm{Ca}^{2+}$ promoted by a genetic mutation of the ryanodine receptor (RYR), a $\mathrm{Ca}^{2+}$-channel protein in the skeletal muscle sarcoplasmic reticulum. In pigs, the genetic cause of PSE meat has been identified as a point mutation in the RYR1 gene at nucleotide 1843, which causes an amino acid substitution (Arg615 to Cys615) in the RYR. This mutation leads to an alteration in $\mathrm{Ca}^{2+}$ homeostasis, hypermetabolism, intense muscle contraction, and malignant hyperthermia in pigs susceptible to porcine stress syndrome. An understanding of this process represents the basis for breeding strategies aimed at eliminating the 
$R Y R 1$ mutation from global pig populations, a strategy that the poultry industry intends to emulate. The aim of this study was to review the subject, with an emphasis on the most recent developments in the field.

Key words: Chicken; Ryanodine receptor; Mutation; Meat quality; Calcium; Porcine stress syndrome

\section{INTRODUCTION}

The mechanisms that control rigor mortis and a decrease in $\mathrm{pH}$ in animal muscles are numerous. Many efforts have been directed at understanding these processes to prevent undesirable outcomes such as pale, soft, and exudative (PSE) meat in pigs, turkeys, and chickens (Fujii et al., 1991; Chiang et al., 2004; Oda et al., 2009; Droval et al., 2012b). The recent application of molecular biology and genetic techniques has enabled detailed investigations into the molecular basis of PSE. Muscle contraction is controlled by calcium $\left(\mathrm{Ca}^{2+}\right)$ release from the endoplasmic reticulum via several channels, one of which is the ryanodine receptor (RYR) protein. Pigs that develop PSE meat are known to have a mutation in the RYR gene. This mutation results in an RYR protein that is still active, but whose altered sequence causes a greater release of calcium in muscle tissues than in those expressing the wild-type RYR protein. PSE characteristics have also been observed in poultry meat, but mutations in the genes that encode RYR in poultry have not yet been identified until now.

\section{PSE meat}

The term PSE meat is derived from its sensorial characteristics, including discoloration, sagging, and oozing at the meat surface. These physical changes result from accelerated muscle metabolism caused by the increased metabolic activities of the animals bred for rapid weight gain to speed up meat production. During the postmortem phase, anaerobic glycolysis degrades muscle glycogen, leading to the formation of lactic acid from pyruvate resulting in a lowered muscle $\mathrm{pH}$. This decrease in $\mathrm{pH}$ is required for proper meat aging and is involved in the process of converting muscle to meat. However, in modern broiler chickens, that are selected for rapid weight gain, the glycogen reserves are rapidly consumed, leading to rapid postmortem glycolysis that lowers the $\mathrm{pH}$ while the carcass is still warm. Olivo et al. (2001) reported that in chicken PSE meat, a final pH of below 5.8 was reached within 15 min postmortem. The sharp drop in $\mathrm{pH}$ and the high temperature of the carcass cause the denaturation of myofibrillar and sarcoplasmic proteins, leading to the loss of meat exudate (Bendall and Wismer-Pedersen, 1962) and impairing the functional properties of meat, which promotes the development of PSE meat (Barbut, 1998; Brewer and McKeith, 1999; Oda et al., 2003) (Figure 1). The development of PSE meat causes problems for the poultry meatprocessing industries, and PSE is estimated to create costs of over US\$200 million in the USA and over US\$36 million in Brazil annually (Oda et al., 2003; Shen et al., 2007). Consumers can detect the visual color abnormality of the PSE breast fillet meat at the point of the purchase and can taste flavor abnormalities due to PSE after cooking (Droval et al., 2012a).

\section{Genetic basis of PSE meat}

The occurrence of PSE meat and its association with a metabolic syndrome was studied 


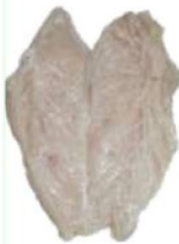

L*53.5 pH5.6

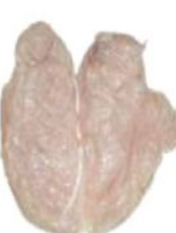

$L^{*} 54.6$

pH5.7

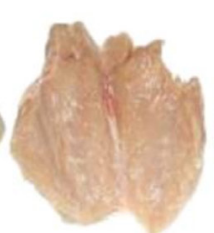

$L^{*} 50.5$

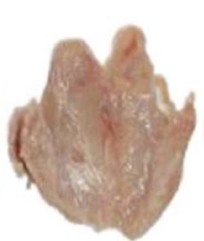

$\mathrm{L}^{*} 47.2$

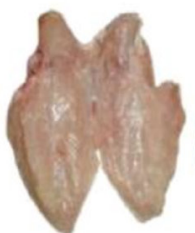

$\mathrm{L}^{*} 44.1$

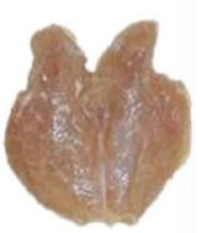

$L^{*} 41.3$

$\mathrm{pH} 6.3$

Figure 1. Chicken breast fillets. Examples of meat color that were directly affected by the final pH (Oda et al., 2003).

first in pigs (Fujii et al., 1991). A direct relationship was found between PSE meat and porcine stress syndrome (PSS), which is a condition that causes symptoms similar to those in malignant hyperthermia (MH), a known syndrome in humans. $\mathrm{MH}$ has been identified in patients exposed to halothane anesthesia inhalation who experience an excessive release of $\mathrm{Ca}^{2+}$ in their tissues during muscle contraction; this increased $\mathrm{Ca}^{2+}$ release causes rapid anaerobic metabolism and muscle rigidity, culminating in increased body temperature and hypermetabolism (Ball and Johnson, 1993).

The mechanism of PSS induction promoted by the excessive release of $\mathrm{Ca}^{2+}$ from the sarcoplasmic reticulum (SR) was proposed by MacLennan and Phillips (1992). These authors claimed that the concentration of $\mathrm{Ca}^{2+}$ in the SR, which stores and releases these ions, regulates muscle contraction, glycolysis, and mitochondrial function. In a normal cycle, $\mathrm{Ca}^{2+}$ is released during muscle contraction in a controlled manner through the SR channels and by using energy obtained from balanced aerobic and glycolytic metabolism.

Thus, $\mathrm{Ca}^{2+}$ release is regulated by the concentration of ATP and $\mathrm{Mg}^{2+}$ as well as by its own concentration in tissues. An ATPase pumps $\mathrm{Ca}^{2+}$ into the SR, initiating the relaxation state. Under the abnormal PSS condition, the $\mathrm{Ca}^{2+}$-releasing channels are sensitive to low concentrations of $\mathrm{Ca}^{2+}$ and remain open, which increases the $\mathrm{Ca}^{2+}$ concentration within the cytoplasm. Thus, muscle contraction is maintained, resulting in muscle rigidity. Aerobic and glycolytic metabolism increases, generating lactic acid, $\mathrm{CO}_{2}$, and heat, which may cause injury to the cell membranes and systemic PSS irregularities (Cheah et al., 1984; Shen et al., 2007). The dysfunction of the RYR1 protein is caused by a point mutation in the RYRI gene (Fujii et al., 1991). In pigs, this mutation consists of a nucleotide substitution at position 1843 of $R Y R 1$, in which a cytosine present in normal animals is replaced by a thymine in mutant animals displaying PSS. This substitution alters the amino acid at position 615 of RYR1, changing arginine present in the wild type to a cysteine in the mutant protein and resulting in dysfunction of the RYR protein. This dysfunction causes an intense muscle contraction and an acceleration of post-mortem glycolysis, which rapidly lowers the $\mathrm{pH}$ in muscle tissue and results in the development of PSE meat. The genetic origin of the RYR1 mutation has also been shown to occur indirectly, as birds exposed to halothane systematically contract their legs (Owens et al., 2000; Marchi et al., 2009a).

\section{Muscle contraction and the RYR protein}

\section{In mammals}

Intracellular calcium signaling and the various steps involved in muscle contraction are very 
complex events. The basic mechanism requires specialized proteins to release, bind, sequester, and restore $\mathrm{Ca}^{2+}$ within cells. Such proteins include RYR, DHPR (dihydropyridine) receptor, and calmodulin $(\mathrm{CaM})$, among others. The structures involved in this mechanism consist of 2 membrane systems, the plasma membrane and the SR, that communicate effectively with each other through specific structures called calcium release units (Protasi et al., 2002). These structures contain proteins that have been identified as key players in this process: the RYRs, large intracellular channels $(\sim 2260 \mathrm{kDa})$ that allow $\mathrm{Ca}^{2+}$ release from the SR in response to the depolarization of the plasma membrane, and DHPRs, which are L-type voltage-dependent $\mathrm{Ca}^{2+}$ channels that are present outside of the muscle cell membranes and control the opening of the RYRs (Protasi, 2002). In addition to these 2 major proteins, recent studies revealed that $\mathrm{CaM}$ is also involved. $\mathrm{CaM}$ is a ubiquitously expressed $\mathrm{Ca}^{2+}$-binding protein that binds proteins, mostly under the $\mathrm{Ca}^{2+}$-dependent conditions. Studies suggest that $\mathrm{CaM}$ binds to RYR and DHPR in a manner that modulates muscle excitation-contraction in skeletal muscle. Nanomolar $\mathrm{Ca}^{2+}$ concentrations inhibit RYR activities (Hamilton et al., 2000), although later reports from Hamilton (2005) indicate that low concentrations of $\mathrm{Ca}^{2+}$ (low $\mu \mathrm{M}$ values) activate RYR; conversely, higher $\mathrm{Ca}^{2+}$ concentrations (in the $\mu \mathrm{M}$ to $\mathrm{mM}$ range) inhibit the activity of the RYR channel. The RYRs, named because of their strong binding affinity to the alkaloid ryanodine, have a molecular weight of approximately $2300 \mathrm{kDa}$ and are formed from a homotetrameric protein comprising polypeptide subunits of 500 and $600 \mathrm{kDa}$. The protein structure has a large cytosolic N-terminal region, a modulatory central region, and a C-terminal domain. In vertebrates, there are $3 \mathrm{RYR}$ isoforms, which are encoded by 3 different genes: RYR1, RYR2, and RYR3 (Sutko and Airey, 1996; Rossi and Sorrentino, 2004). In mammals, RYR1 is expressed at high levels in skeletal muscle fibers, and RYR2 is expressed primarily in cardiac myocytes and brain; in addition, both have been detected in the central nervous system and other peripheral tissues, likely participating in signal transduction mechanisms. RYR3 appears to be expressed in various mammalian tissues, including skeletal muscle, but at levels 20-50-fold lower compared to $R Y R 1$, although $R Y R 1$ is restricted to the diaphragm (Rossi and Sorrentino, 2004).

\section{In other animals}

In poultry skeletal muscle, and in amphibians and fish, two RYR eptor isoforms coexist and are co-expressed, unlike mammalian muscle cells in which only RYR1 is expressed (Airey et al., 1990; Murayama and Ogawa, 1992). These 2 isoforms are called $\alpha$ and $\beta$ and they correspond to the mammalian RYR1 and RYR3 proteins, respectively. A third isoform, RYR2, which is recognized by the mammalian RYR2 antibody, was found in the heart tissue of hens and appears to be homologous to the mammalian RYR2 (Ottini et al., 1996).

The isoforms $\alpha R Y R$ and $\beta R Y R$ are arranged in precise locations within the skeletal and cardiac muscles, in structures known as triads and dyads, respectively, and have different activation mechanisms. These structures represent complexes that form junctions between the SR and the T tubule system; they ensure a direct interaction between DHPR and RYR, and this association is essential for activating the excitation-contraction muscle mechanism. Thus, $\alpha \mathrm{RYR}$ is physically coupled with DHPR and is subject to the conformational changes in DHPR, which are induced by alterations in depolarization within the membrane and cause muscle contraction. The cardiac fibers, in contrast, are not physically associated with DHPRs and are instead activated by a $\mathrm{Ca}^{2+}$-induced $\mathrm{Ca}^{2+}$-release mechanism (Felder and Franzini-Armstrong, 2002). For $\beta R Y R$ in species that possess this $\mathrm{Ca}^{2+}$ channel in skeletal muscle in the same proportion as the $\alpha \mathrm{RYR}$ located in a parajunctional region immediately adjacent to the SR junctional region, $\beta R Y R$ activation would be indirect during 
the excitation-contraction event (Murayama and Kurebayashi, 2011). In summary, 2 mechanisms have been proposed to explain the release of calcium: interaction of the RYR voltage sensors with DHPR and the mechanism of $\mathrm{Ca}^{2+}$-induced $\mathrm{Ca}^{2+}$-release. The first mechanism is the most accepted, whereas the second remains controversial. However, it is thought that distinct processes are involved in the activation of $\mathrm{Ca}^{2+}$ release from the SR by different RYR isoforms. In the case of non-mammalian vertebrates in which 2 RYR isoforms are present in similar amounts, it can be assumed that the $\alpha R Y R$ isoform is activated by an interaction with DHPR, while $\beta R Y R$ responds to $\mathrm{Ca}^{2+}$-ion activation (Percival et al., 1994).

Figure 2 shows a schematic model of the different functions of these 2 isoforms during muscle excitation-contraction (Strasburg and Chiang, 2003). The behaviors of the $\alpha$ and $\beta$ RYR isoforms differ depending on whether they are activated by $\mathrm{Ca}^{2+}$ or by ATP. In the case of $\beta$ RYR, $\mathrm{Ca}^{2+}$ appears to destabilize the closed state, whereas ATP stabilizes the open state. The different roles of the 2 isoforms are accentuated in the absence of ATP, in which $\alpha$ RYR exhibits a large number of openings for a very short period. The physiological significance of this event needs to be determined, but it is speculated that these channels are more efficient in supplying the $\mathrm{Ca}^{2+}$ needed for the activation of adjacent channels than in increasing the concentration of $\mathrm{Ca}^{2+}$ in the vicinity of the myofibrils.

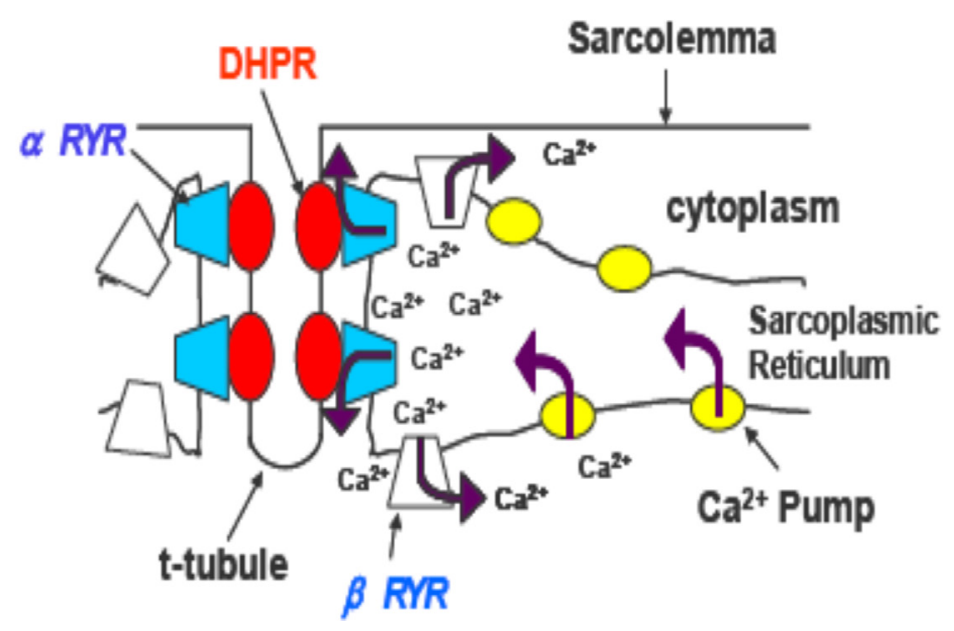

Figure 2. Schematic model of the excitation-contraction mechanism in the skeletal muscle of birds. The T-tubule depolarization causes the release of $\mathrm{Ca}^{2+}$ by $\alpha \mathrm{RYR}$, which is physically coupled to DHPR. The local increase in $\mathrm{Ca}^{2+}$ causes the opening of $\beta R Y R$, located peripherally to the tubule's T/sarcoplasmic reticulum junction. The calcium ions are recaptured during the muscle relaxation by the calcium pump (Strasburg and Chiang, 2003).

Oda et al. (2009) evaluated $R Y R$ gene expression of the $\alpha$ and $\beta$ isoforms in the muscle cells of PSE broiler chicken meat and non-PSE breast meat. They also analyzed the expression of these genes in a broiler line and a layer line in samples categorized as either normal or PSE by $\mathrm{L}^{*}$ and $\mathrm{pH}_{24 \mathrm{~h}}$ values. The authors found no difference in $\alpha R Y R$ expression in neither line nor meat quality. However, a decrease in $\beta R Y R$ expression was observed in the PSE meat from both lines. These results provided the first evidence that chicken PSE meat may result from excess cytosolic $\mathrm{Ca}^{2+}$ caused by the differential expression of the RYR proteins. 


\section{Molecular biology and poultry $R Y R$ mutation}

As previously mentioned, RYR is extremely large $(\sim 2300 \mathrm{kDa})$, and the $R Y R$ gene in humans contains approximately $159,000 \mathrm{bp}$, divided into 106 exons $(\sim 15,000 \mathrm{bp}), 2$ of which give rise to the different RYR isoforms through alternative splicing of mRNA (Phillips et al., 1996).

The cytoplasmic portion of RYR is made up of 4 subunits $(\sim 500 \mathrm{kDa}$ each $)$ and is square in shape, leading to the formation of "legs", which are structures localized at the junction between the T tubules and the SR. There is a close association in this region with the outer-membrane regions, where another molecule responsible for muscle contraction, DHPR, is located (FranziniArmstrong and Jorgensen, 1994). The N-terminal region of RYR, composed of $\sim 4000$ amino acids, interacts with DHPR, whereas the C-terminal region contains $\sim 1000$ amino acids and forms the 4 transmembrane domains (M1, M2, M3, and M4) of RYR (Brini, 2004). A schematic model of the large N-terminal region is shown in Figure 3. The junction between the T tubules and the SR is occupied by the N-terminal portion of RYR, and this N-terminal region interacts with DHPR. In addition, many human RYRl mutations associated with $\mathrm{MH}$ are located in the $\mathrm{N}$-terminal region.

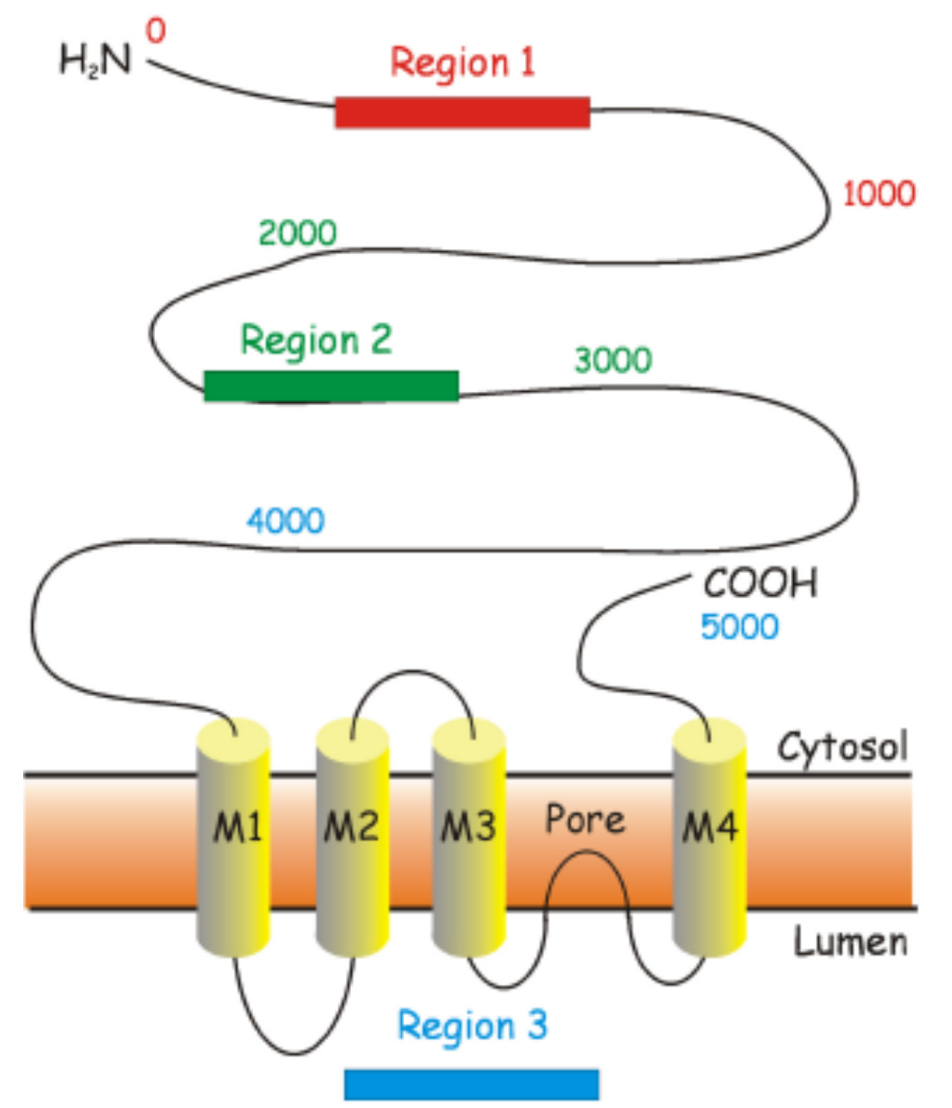

Figure 3. Schematic diagram of regions with different hotspot mutations for $R Y R$. Region $1=$ amino acids 0-1000; Region 2 = amino acids 2000-3000; Region 3 = amino acids 4000-5000. M1, M2, M3 and M4 = transmembrane domains. Adapted from Brini (2004). 
This is also true for pigs, making this protein region a good candidate for mutational analysis in other animals. The N-terminal region between amino acids 1 and 614 is also known as hotspot 1; it contains not only mutations that impair the function of RYR in humans with $\mathrm{MH}$, but also the mutation that causes PSE in pig meat. In addition to this hotspot, there are 2 other regions, located between amino acids 2162-2458 (hotspot region 2) at the N-terminus and between amino acids 4800-4900 (hotspot 3 region) in the C-terminal region, which are important protein domains that control the sensitivity of the RYR channel to regulatory compounds and that modulate $\mathrm{Ca}^{2+}$ release (Strasburg and Chiang, 2009). Chiang et al. (2004) screened turkey DNA and cDNA in the region encompassing amino acid residues 36-615 in the $\alpha$ RYR, which corresponds to the region of the human hotspot in RYR1. The authors did not identify any of the mutations in the RYRl gene found in pigs; however, upon examining the $R Y R 1 \mathrm{cDNA}$, they identified 3 different transcripts for the region corresponding to the cDNA nucleotides 1231-1947 in the human RYR1 sequence. This included a 717-bp transcript similar to the mammalian skeletal muscle RYR1, the AS- 81 transcript, which contains a deletion of 81 bases at the beginning of exon 13, and the AS-193 transcript, which lacks all 193 bases of exon 13. According to Chiang et al. (2004), the deletion within $\alpha$ RYR seems to affect the interaction between calcium channels and DHPR, which, as a result, influences the regulation of calcium release. The chicken $\alpha$ RYR protein and cDNA sequences can be accessed from GenBank (accessions X95266, XM_424193, XM_428139, XM_427376).

Ziober et al. (2009) reported the sequence of the cDNA encoding the chicken region hotspot $1 \alpha R Y R$ (corresponding to amino acids 386-540 relative to the turkey sequence) and analyzed the N-terminal portion of $\alpha \mathrm{RYR}$. This analysis showed that the chicken transcripts share 97 and $74 \%$ sequence identity with the turkey $\alpha R Y R$ and mammalian $R Y R 1$ sequences, respectively (Figure 4). Note that the sequences of the chicken $\alpha R Y R$ transcripts described by Ziober et al. (2009) show no similarity to the Gallus gallus genomic sequences in the GenBank database. The reason for this discrepancy may be that the region of the $\alpha R Y R$ transcript sequenced by Ziober et al. (2009) was similar to a region on chromosome 3 from G. gallus that contains a gap, representing a DNA fragment with a series of undetermined nucleotides.

A.

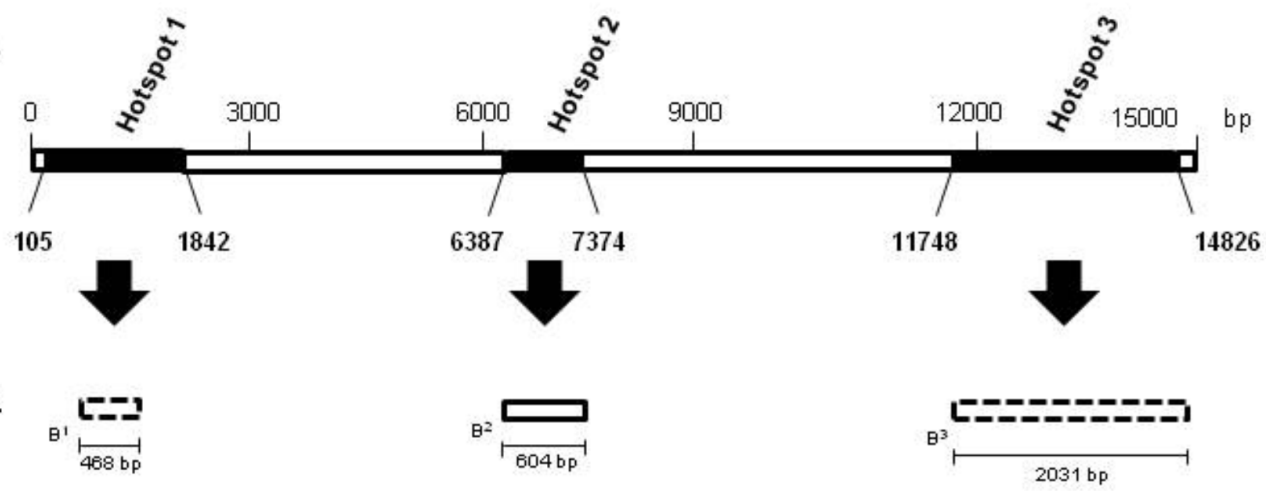

Figure 4. Schematic representation of ryanodine receptor (RYR) domains. A. Three regions of human RYR1 amino acid sequence (black) are referred to as hotspots because of the clustering of mutations within these domains. Amino acid residue numbers, which serve as boundaries of the hotspots. B. Sequences of the hotspot regions 2 and 3 of Gallus gallus $\left(\mathrm{B}^{2}=604-\mathrm{bp}\right.$ DNA from hotspot 2 of G. gallus are known. $\mathrm{B}^{3}=2031$-bp transcript from hotspot 3 of G. gallus are known). 
Ottini et al. (1996) sequenced an $\alpha R Y R$ transcript; however, this sequence was found to correspond to the $\mathrm{C}$-terminal region of the $\alpha \mathrm{RYR}$ protein, which does not include the region analyzed by Ziober et al. (2009), corresponding to the $\mathrm{N}$-terminal part of the $\alpha R Y R$ transcript. Thereafter, Ziober et al. (2010) examined the relationship between the formation of PSE meat under halothane exposure and heat stress and the $\alpha R Y R$ transcripts from chicken. The authors also sequenced a portion of the chicken mRNA that corresponded to the hotspot $R Y R 1$ gene region and studied the effects of different treatments, such as heat stress and exposure to halothane. Ziober et al. (2010) sequenced 18 regions of chicken cDNA and reported any nucleotide deletions and substitutions. Many of the substitution mutations identified by these authors were synonymous or led to tolerable changes in protein structure, whereas the deletions resulted in transcripts with premature stop codons leading to truncated proteins that were non-functional (Table 1).

Table 1. Results of the sequence analysis of the 18 samples under halothane treatment and heat stress as well as the resulting meat quality.

\begin{tabular}{|c|c|c|c|c|c|c|c|c|}
\hline Sample & Exp. to halothane & Heat stress & Meat quality & Alteration & Nucleotide & Protein & Alteration & Effect on protein \\
\hline $\begin{array}{l}\mathrm{H}+\mathrm{HS} 3 \\
\mathrm{H} 1\end{array}$ & $\begin{array}{l}\text { Yes } \\
\text { Yes }\end{array}$ & $\begin{array}{l}\text { Yes } \\
\text { No }\end{array}$ & $\begin{array}{l}\text { Normal } \\
\text { Normal }\end{array}$ & $\begin{array}{l}\text { Substitution: } \mathrm{T} \rightarrow \mathrm{A} \\
\text { Deletion: } \mathrm{G} \\
\text { Substitution: } \mathrm{G} \rightarrow \mathrm{A}\end{array}$ & $\begin{array}{r}\# 12 \\
\# 363 \\
\# 27\end{array}$ & $\begin{array}{l}\# 4 \\
\# 9\end{array}$ & $\begin{array}{l}\mathrm{L} \rightarrow \mathrm{H} \\
\mathrm{G} \rightarrow \mathrm{A} \\
(\mathrm{CRF}) \\
(\# 16) \mathrm{TI}\end{array}$ & $\begin{array}{l}\text { Tolerable } \\
\text { Truncated }\end{array}$ \\
\hline $\mathrm{H}+\mathrm{HS} 5$ & Yes & Yes & PSE & $\begin{array}{l}\text { Substitution: } \mathrm{G} \rightarrow \mathrm{A} \\
\text { Substitution: } \mathrm{A} \rightarrow \mathrm{G}\end{array}$ & $\begin{array}{r}\# 31 \\
\# 443\end{array}$ & \#148 & $\mathrm{T} \rightarrow \mathrm{A}$ & $\begin{array}{l}\text { Synonymous } \\
\text { Tolerable }\end{array}$ \\
\hline $\mathrm{H}+\mathrm{HS} 6$ & Yes & Yes & PSE & $\begin{array}{l}\text { Deletion: } \mathrm{T} \\
\text { Substitution: } \mathrm{A} \rightarrow \mathrm{G} \\
\text { Substitution: } \mathrm{A} \rightarrow \mathrm{G}\end{array}$ & $\begin{array}{r}\# 56 \\
\# 305 \\
\# 366\end{array}$ & \#19 & $\begin{array}{l}\mathrm{Y} \rightarrow \mathrm{T} \\
(\mathrm{CRF}) \\
(\# 34) \mathrm{TI}\end{array}$ & Truncated \\
\hline $\mathrm{C}+\mathrm{HS} 3$ & No & Yes & Normal & $\begin{array}{l}\text { Substitution: } \mathrm{T} \rightarrow \mathrm{C} \\
\text { Substitution: } \mathrm{A} \rightarrow \mathrm{G}\end{array}$ & $\begin{array}{l}\# 110 \\
\# 290\end{array}$ & $\begin{array}{l}\# 37 \\
\# 97\end{array}$ & $\begin{array}{l}\mathrm{S} \rightarrow \mathrm{P} \\
\mathrm{I} \rightarrow \mathrm{V}\end{array}$ & $\begin{array}{l}\text { Tolerable } \\
\text { Tolerable }\end{array}$ \\
\hline C3 & No & No & Normal & $\begin{array}{l}\text { Substitution: } \mathrm{T} \rightarrow \mathrm{C} \\
\text { Substitution: } \mathrm{T} \rightarrow \mathrm{C} \\
\text { Substitution: } \mathrm{C} \rightarrow \mathrm{T}\end{array}$ & $\begin{array}{l}\# 110 \\
\# 275 \\
\# 344\end{array}$ & $\begin{array}{l}\# 37 \\
\# 91\end{array}$ & $\underset{\mathrm{TI}}{\mathrm{S} \rightarrow \mathrm{P}}$ & $\begin{array}{l}\text { Tolerable } \\
\text { Truncated }\end{array}$ \\
\hline $\mathrm{H} 2$ & Yes & No & Normal & $\begin{array}{l}\text { Deletion: } \mathrm{C} \\
\text { Substitution: } \mathrm{T} \rightarrow \mathrm{C}\end{array}$ & $\begin{array}{l}\# 151 \\
\# 352\end{array}$ & $\# 51$ & $\begin{array}{c}\mathrm{I} \rightarrow \mathrm{S} \\
(\mathrm{CRF}) \\
(\# 95) \mathrm{TI}\end{array}$ & Truncated \\
\hline $\mathrm{H}+\mathrm{HS} 4$ & Yes & Yes & PSE & $\begin{array}{l}\text { Deletion: } \mathrm{C} \\
\text { Substitution: } \mathrm{T} \rightarrow \mathrm{C}\end{array}$ & $\begin{array}{l}\# 151 \\
\# 352\end{array}$ & $\# 51$ & $\begin{array}{c}\mathrm{I} \rightarrow \mathrm{S} \\
(\mathrm{CRF}) \\
(\# 95) \mathrm{TI}\end{array}$ & Truncated \\
\hline $\mathrm{C} 2$ & No & No & Normal & No alteration & & & & \\
\hline $\mathrm{C} 1$ & No & No & PSE & No alteration & & & & \\
\hline $\mathrm{C}+\mathrm{HS} 1$ & No & Yes & PSE & No alteration & & & & \\
\hline $\mathrm{C}+\mathrm{HS} 4$ & No & Yes & PSE & No alteration & & & & \\
\hline $\mathrm{C}+\mathrm{HS} 5$ & No & Yes & PSE & No alteration & & & & \\
\hline $\mathrm{C}+\mathrm{HS} 2$ & No & Yes & Normal & No alteration & & & & \\
\hline $\mathrm{H} 3$ & Yes & No & PSE & No alteration & & & & \\
\hline $\mathrm{H} 4$ & Yes & No & PSE & No alteration & & & & \\
\hline $\mathrm{H}+\mathrm{HS} 2$ & Yes & Yes & PSE & No alteration & & & & \\
\hline $\mathrm{H}+\mathrm{HS} 1$ & Yes & Yes & Normal & No alteration & & & & \\
\hline
\end{tabular}

Identification of the nucleotide alterations, proteins, and the probable effect on the protein structure is also indicated (Ziober et al., 2010). $\mathrm{H}+\mathrm{HS}=$ halothane treatment and heat stress; $\mathrm{C}=$ control group; $\mathrm{C}+\mathrm{HS}=$ heat stress without halothane treatment; $\mathrm{CRF}=$ change of the reading frame; $\mathrm{TI}=$ translation interrupted.

However, these changes in mRNA were associated with the stress generated in birds by exposing them to heat, used to induce the formation of PSE meat, and also by exposure to the anesthetic halothane, which was used to select for birds prone to developing PSE meat (Marchi et al., 2009b). It is known that stressors can interfere with $\alpha R Y R$ gene expression, but it was not 
possible to associate these changes directly with the occurrence of PSE meat, as altered mRNA transcripts were found in samples from both normal meat and PSE meat. As gene expression can be modulated by the environment, Droval et al. (2012b) sequenced a portion of the chicken $R Y R$ gene corresponding to the hotspot region 2 in human $R Y R$ and identified a polymorphism consisting of a replaced guanidine nucleotide at a specific position of the gene (Figure 5).

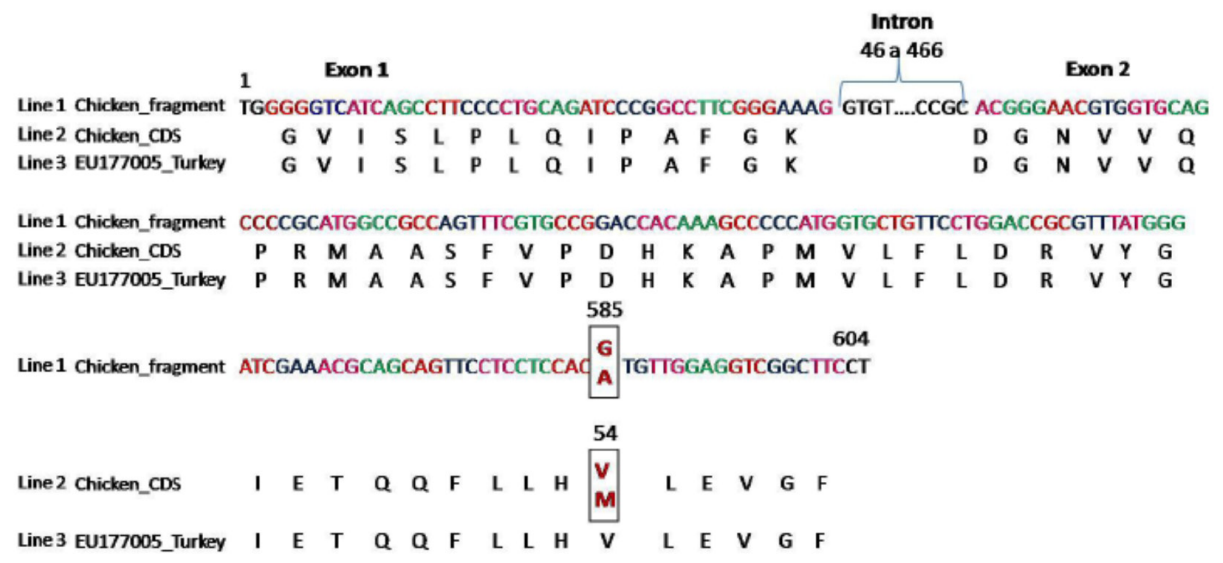

Figure 5. Alignment of the nucleotide sequence of the fragment obtained from chickens with the translation of the amino acid sequence, indicating the nucleotide (position 585) and amino acid (position 54) modified in the coding region. Line $1=$ nucleotides colored in red, blue, pink, and green correspond to the codons of the coding region and the black noncoding region. Line 2 = amino acid sequence of $\alpha \mathrm{RYR}$ in chicken. Black indicates the normal sequences and red indicates the altered amino acid sequence. Line $3=$ amino acid sequence of $\alpha$ RYR in turkey (2455-2513) (Droval et al., 2012b).

However, as this polymorphism occurred in both the normal meat and the PSE meat samples, it was not possible to correlate the presence of the polymorphism with PSE meat in poultry.

\section{CONCLUSIONS}

The development of PSE meat represents an economic problem for the poultry industry worldwide. Although genetic studies demonstrated that PSE pig meat is associated with a mutation in the RYRl gene encoding the RYR1 protein, no RYRI gene mutations that are involved in the development of PSE meat in chickens have yet been discovered. In turkeys, some variants in RYR transcripts were identified, but none was related to changes in RYR DNA or to the occurrence of PSE meat. Thus, the gene sequences involved in PSE meat formation, especially the $R Y R$ gene, are still being evaluated to identify mutations that would explain a similar genetic origin of poultry PSE meat as in pigs, or to identify a molecular marker for PSE meat formation. Such information might lead to the development of a molecular diagnostics tool that could be used to predict the development of abnormal broiler chicken meat.

\section{REFERENCES}

Airey JA, Beck CF, Murakami K, Tanksley SJ, et al. (1990). Identification and localization of two triad junctional foot protein isoforms in mature avian fast twitch skeletal muscle. J. Biol. Chem. 265: 14187-14194.

Ball SP and Johnson KJ (1993). The genetics of malignant hyperthermia. J. Med. Gen. 30: 89-93. 
Barbut S (1998). Estimating the magnitude of the PSE problem in poultry. J. Muscle Foods 9: 35-49.

Bendall JR and Wismer-Pedersen J (1962). Some properties of the fibrillar proteins of normal and watery pork muscle. $J$. Food. Sci. 27: 144-159.

Brewer MS and McKeith FK (1999). Consumer-rated quality characteristics as related to purchase intent of fresh pork. $J$. Food Sci. 64: 171-174.

Brini M (2004). Ryanodine receptor defects in muscle genetic diseases. Biochem. Biophys. Res. Commun. 322: 1245-1255.

Cheah KS, Cheah AM, Crosland AR, Casey JC, et al. (1984). Relationship between $\mathrm{Ca}^{2+}$ release, sarcoplasmic $\mathrm{Ca}^{2+}$, glycolysis and meat quality in halothane-sensitive and halothane-insensitive pigs. Meat Sci. 10: 117-130.

Chiang W, Allison CP, Linz JE and Strasburg GM (2004). Identification of two aRYR alleles and characterization of $\alpha$ RYR transcript variants in turkey skeletal muscle. Gene 330: 177-184.

Droval AA, Benassi VT, Rossa A, Prudencio SH, et al. (2012a). Consumer attitudes and preferences regarding pale, soft, and exudative broiler breast meat. J. Appl. Poult. Res. 21: 502-507.

Droval AA, Binneck E, Marin SR, Paiao FG, et al. (2012b). A new single nucleotide polymorphism in the ryanodine gene of chicken skeletal muscle. Genet. Mol. Res. 11: 821-829.

Felder E and Franzini-Armstrong C (2002). Type 3 ryanodine receptors of skeletal muscle are segregated in a parajunctional position. Proc. Natl. Acad. Sci. U. S. A. 99: 1695-1700.

Franzini-Armstrong C and Jorgensen AO (1994). Structure and development of E-C coupling units in skeletal muscle. Annu. Rev. Physiol. 56: 509-534.

Fujii J, Otsu K, Zorzato F, de Leon S, et al. (1991). Identification of a mutation in porcine ryanodine receptor associated with malignant hyperthermia. Science 253: 448-451.

Hamilton SL (2005). Ryanodine receptors. Cell Calcium 38: 253-260.

Hamilton SL, Serysheva I and Strasburg GM (2000). Calmodulin and Excitation-Contraction Coupling. News Physiol. Sci. 15: 281-284.

MacLennan DH and Phillips MS (1992). Malignant hyperthermia. Science 256: 789-794.

Marchi DF, Oba A, Ziober IL, Soares AL, et al. (2009a). Development of a gas chamber for detecting broiler chicken halothane sensitivity and PSE (Pale, Soft, Exudative) meat formation. Braz. Arch. Biol. Technol. 52: 189-194.

Marchi DF, Trindade MA, Oba A and Soares AL (2009b). Sensitivity to halothane and its relationship to the development of PSE (Pale, Soft, Exudative) meat in female lineage broilers. Braz. Arch. Biol. Technol. 52: 219-223.

Murayama T and Ogawa Y (1992). Purification and characterization of two ryanodine-binding protein isoforms from sarcoplasmic reticulum of bullfrog skeletal muscle. J. Biochem. 112: 514-522.

Murayama T and Kurebayashi N (2011). Two ryanodine receptor isoforms in nonmammalian vertebrate skeletal muscle: possible roles in excitation-contraction coupling and other processes. Prog. Biophys. Mol. Biol. 105: 134-144.

Oda SHI, Schneider J, Soares AL, Barbosa DML, et al. (2003). Detecção de cor de filés de peito de frango. Rev. Nac. Carne 27: 30-34.

Oda SHI, Nepomuceno AL, Ledur MC, Oliveira MCN, et al. (2009). Quantitative differential expression of alpha and beta ryanodine receptor genes in PSE (Pale, Soft, Exudative) meat from two chicken lines: broiler and layer. Braz. Arch. Biol. Technol. 52: 1519-1525.

Olivo R, Soares AL, Ida EI and Shimokomaki M (2001). Dietary vitamin E inhibits poultry PSE and improves meat functional properties. J. Food Biochem. 25: 271-283.

Ottini L, Marziali G, Conti A, Charlesworth A, et al. (1996). Alpha and beta isoforms of ryanodine receptor from chicken skeletal muscle are the homologues of mammalian RyR1 and RyR3. Biochem. J. 315: 207-216.

Owens CM, Matthews NS and Sam AR (2000). The use of halothane gas to identify turkeys prone to developing pale, exudative meat when transported before slaughter. Poult. Sci. 79: 789-795.

Percival AL, Williams AJ, Kenyon JL, Grinsell MM, et al. (1994). Chicken skeletal muscle ryanodine receptor isoforms: ion channel properties. Biophys. J. 67: 1834-1850.

Phillips MS, Fujii J, Khanna VK, DeLeon S, et al. (1996). The structural organization of the human skeletal muscle ryanodine receptor (RYR1) gene. Genomics 34: 24-41.

Protasi F (2002). Structural interaction between RYRs and DHPRs in calcium release units of cardiac and skeletal muscle cells. Front Biosci. 7: d650-d658.

Protasi F, Paolini C, Nakai J, Beam KG, et al. (2002). Multiple regions of RyR1 mediate functional and structural interactions with $\alpha$ (1S)-dihydropyridine receptors in skeletal muscle. Biophys. $J .83: 3230-3244$.

Rossi D and Sorrentino V (2004). The ryanodine receptors gene family: expression and functional meaning. Basic Appl. Myol. 14: 323-343.

Shen QW, Underwood KR, Means WJ, McCormick RJ, et al. (2007). The halothane gene, energy metabolism, adenosine monophosphate-activated protein kinase, and glycolysis in postmortem pig longissimus dorsi muscle. J. Anim. Sci. 85: 1054-1061. 
Strasburg GM and Chiang W (2003). Genetic Basis for Pale, Soft and Exudative Turkey Meat. Proceedings of the 56th American Meat Science Association, Reciprocal Meat Conference, Columbia, 17-22.

Strasburg GM and Chiang W (2009). Pale, soft, exudative turkey - The role of ryanodine receptor variation in meat quality. Poult. Sci. 88: 1497-1505.

Sutko JL and Airey JA (1996). Ryanodine receptor $\mathrm{Ca}^{2+}$ release channels: does diversity in form equal diversity in function? Physiol. Rev. 76: 1027-1071.

Ziober IL, Paião FG, Marin SRR, Binneck E, et al. (2009). Molecular cloning of RYR-hotspot 1 region from broiler chicken. Braz. Arch. Biol. Technol. 52: 225-231.

Ziober IL, Paião FG, Marchi DF, Coutinho LL, et al. (2010). Heat and chemical stress modulate the expression of the alpha-RYR gene in broiler chickens. Genet. Mol. Res. 9: 1258-1266. 